\title{
Genotypic variation rather than ploidy level determines functional trait expression in a foundation tree species in the presence and absence of environmental stress
}

\author{
Michael Eisenring ${ }^{1}$, Richard Lindroth ${ }^{2}$, Amy Flansburg ${ }^{2}$, Noreen Giezendanner ${ }^{2}$, Karen \\ Mock $^{3}$, and Eric Kruger ${ }^{4}$ \\ ${ }^{1}$ Swiss Federal Institute for Forest Snow and Landscape Research \\ ${ }^{2}$ University of Wisconsin \\ ${ }^{3}$ Utah State University \\ ${ }^{4}$ University of Wisconsin-Madison
}

February 2, 2022

\begin{abstract}
Background and Aims: At the population level, genetic diversity is a key determinant of a tree species' capacity to cope with stress. However, little is known about the relative importance of the different components of genetic diversity for tree stress responses. We compared how two sources of genetic diversity, genotype and cytotype (i.e. differences in ploidy levels) influence growth, phytochemical, and physiological traits of Populus tremuloides in the presence and absence of environmental stress.

Methods: In a series of field studies, we first assessed variation in traits across diploid and triploid aspen genotypes from Utah and Wisconsin under nonstressed conditions. In two follow-up experiments, we exposed diploid and triploid aspen genotypes from Wisconsin to individual and interactive drought stress and defoliation treatments and quantified trait variations under stress.

Key Results: We found that 1) tree growth and associated traits did not differ significantly between ploidy levels under nonstressed conditions. Instead, variation in tree growth and most other traits was driven by genotypic and population differences. 2) Genotypic differences were critical for explaining variation of most of functional traits and their responses to stress. 3) Ploidy level played a subtle role in shaping traits and trait stress responses, as its influence was typically obscured by genotypic differences. 4) As an exception to the third conclusion, we showed that triploid trees expressed minimally higher levels of foliar defenses, photosynthesis, and rubisco activity under well-watered conditions, and displayed slightly greater drought resilience than diploids.
\end{abstract}

Conclusion: Although ploidy level can strongly influence the ecology of tree species, those effects may be relatively small in contrast to the effects of genotypic variation in highly diverse species.

\section{INTRODUCTION}

Climate change-associated drought events are impacting forest ecosystem structure, function and distribution worldwide at a magnitude and speed unparalleled in human history (Allen et al. 2015; Anderegg et al. 2013a; Batllori et al. 2020). In coming years, droughts are predicted to further increase in intensity and frequency in many parts of the world, including temperate regions (Gazol et al. 2017; Lecina-Diaz et al. 2021; Samaniego et al. 2018). The capacity of many forest trees to persist in future environments will be determined by mechanisms that enable them to cope with recurrent and intense drought stress on a regular basis.

Drought impacts on forests ecosystems are frequently coupled to other climate change-related stressors (Millar and Stephenson 2015). Drought and warming, for example, can facilitate outbreaks of insect herbivores (Anderegg et al. 2015; Kolb et al. 2016; Seidl et al. 2017). Consequently, trees must cope with multiple, potentially interacting abiotic and biotic stressors (Aber et al. 2001; Niinemets 2010). To advance our 
understanding of how climate change affects tree performance, controlled experiments are needed to disentangle the individual and interactive effects of multiple co-occurring stressors and to elucidate the underlying mechanisms that enable trees to cope with environmental stress.

Genetic diversity is a key determinant of a plant species' ability to evolve in response to environmental stress (Estravis-Barcala et al. 2020; Schueler et al. 2013). Conspecific genotypes can vary considerably in trait expression and phenotypic plasticity - i.e., the capacity to express different phenotypes under different environmental conditions (Bradshaw 1965; Valladares et al. 2007). Different genotypes from the same plant species can show marked differences in their responses to abiotic (Albert et al. 2010; Cooper et al. 2019; Huang et al. 2015; Kreyling et al. 2019) and biotic (Aartsma et al. 2019; Barton et al. 2015; Rubert-Nason et al. 2015; Silfver et al. 2009; Wurst et al. 2008) stress. Intraspecific genotypic variation is thus an important element facilitating ecological and evolutionary responses of plant populations to environmental change (Westerband et al. 2021).

Another less-understood aspect of genetic diversity in plants is polyploidy - i.e., the possession of more than two paired sets of chromosomes in somatic cells. Naturally occurring polyploid cytotypes can differ from diploid cytotypes in many traits, including growth, chemistry and physiology (Diallo et al. 2016; Greer et al. 2018; Li et al. 1996; Meng et al. 2014; Niwa and Sasaki 2003). Polyploidy has long been considered a mechanism that could increase plant tolerance to stressful environments (Levin 1983; Madlung 2013; Van de Peer et al. 2021; Van de Peer et al. 2017). However, the importance of polyploidy as a stresstolerance enhancer is still debated and the mechanisms underlying ploidy-driven stress responses remain largely unknown (Fox et al. 2020; Van de Peer et al. 2021; Van de Peer et al. 2017).

For plant species or populations with a high intraspecific genotypic and cytotype diversity, both genotype and cytotype may be important for plant stress adaptation. Yet, the relevance of trait variation due to genotype relative to variation due to cytotype has rarely been documented (but see Blonder et al. (2021), Wei et al. (2020)). Few if any results have been published from controlled experiments that simultaneously evaluated the significance of trait variation due to genotype and cytotype in a climate change context. Trembling aspen (Populus tremuloides; hereafter "aspen"), the most broadly distributed tree in North America (Elias and Little 1980), is among the species predicted to be most severely affected by climate change (Anderegg et al. 2013b; Ashraf et al. 2015; Zolkos et al. 2015). In recent decades, aspen stands have experienced largescale declines throughout the Intermountain West of North America (Rehfeldt et al. 2009; Stanke et al. 2021). These declines have been attributed in part to extended drought events and insect outbreaks (Chen et al. 2018; Worrall et al. 2013). Aspen is characterized by high levels of intraspecific genetic diversity and phenotypic plasticity (Barker et al. 2019; Mitton and Grant 1996). Aspen is generally diploid (individuals with two sets of chromosomes). Autopolyploid, triploid genotypes (i.e., triploidy wherein all three sets of chromosomes derive from the same species rather than from the hybridization of two species) appear to be common across the western USA but are rare in most other parts of the USA, including the Great Lakes Region (Every and Wiens 1971; Mock et al. 2012).

Preliminary research suggests that larger aspen clones are frequently triploid (Bishop et al. 2019; Mock et al. 2008), and that triploids grow faster and differ in photosynthetic capacity when compared with their diploid counterparts (DeRose et al. 2015; Greer et al. 2018; Mock et al. 2008). Additionally, Blonder et al. (2021) reported that triploid aspen have reduced recruitment on drought-prone plots relative to diploids. Finally, Greer et al. (2018) found that triploid aspen may have a lower resilience than diploids to drought stress, due to larger stomatal size and lower stomal sensitivity to increasing vapor pressure deficit.

The goal of this study was to explore the effects of autopolyploidy levels (cytotype), in the context of conventional genotypic variation among sexually generated individuals, on both trait expression and its plasticity, in aspen. In the first of three field studies, we assessed variation in growth, biomass allocation, phytochemistry and leaf physiology across diploid and triploid aspen genotypes from the Intermountain West (Utah, USA) and the Great Lakes region (Wisconsin, USA). In two follow-up experiments involving the same diploid and triploid genotypes from Wisconsin, we evaluated plasticity in response to two environmental stressors that heavily influence aspen performance: drought and defoliation (simulated herbivory). In Experiment 2, 
we assessed how ploidy levels were associated with growth, chemistry, and physiology of trees subjected to moderate drought stress, defoliation, and their combination. In Experiment 3, we explored how ploidy levels influenced aspen recovery from prolonged drought stress and pre-drought defoliation. We aimed to disentangle the effects of ploidy level per se from the effects of different genotypes on trait variation. Hence, for all three experiments, we quantified ploidy effects by using individual genotypes as statistical units, allowing us to incorporate individual genotypic variation.

\section{MATERIALS AND METHODS}

\section{Experimental overview}

We conducted three experiments with $P$. tremuloides planted in outdoor mesocosms in or near Madison, WI, USA. The first experiment took place at West Madison Agricultural Experiment Station and the others occurred on the campus of the University of Wisconsin-Madison. In Experiment 1, identical sets of 32 aspen genotypes, including 16 from Utah and 16 from Wisconsin (eight diploid and eight triploid genotypes from each location, two ramets per genotype), were planted in each of 15 blocks (Appendix 1). Across these genotypes, we assessed the manner in which population effects and polyploidy influenced aspen growth, phytochemistry, and physiology in the absence of discernible stress (i.e., full sunlight, ample edaphic resources, negligible herbivory in all mesocosms).

For Experiments 2 and 3, identical sets of 16 aspen genotypes (eight diploid and eight triploid, one ramet per genotype) from Wisconsin were grown in each of 22 and ten mesocosms, respectively. In Experiment 2, we investigated how polyploidy affected aspen growth, chemistry, and physiology when exposed to recurring, moderate drought stress and simulated herbivory. Trees were exposed to two water (well-watered and drought-stressed) and two defoliation treatments ( $0 \%$ and $50 \%$ defoliation). Drought stress and defoliation treatments were fully crossed $(2 \times 2$ factorial $)$. Treatment combinations that included defoliation were replicated five times, whereas treatment combinations with no defoliation were replicated six times (i.e., we ended up with five droughted/defoliated, five well-watered/defoliated, six droughted/nondefoliated, and six well-watered/nondefoliated mesocosms).Treatments were spatially blocked (Appendix 1). In Experiment 3, we explored how ploidy, genotypic differences and pre-drought herbivory affected the recovery of aspen after an extensive drought treatment. In this experiment, trees were exposed to drought stress, with or without $50 \%$ defoliation. Defoliation treatments were replicated five times (i.e., five extensive droughted/defoliated, and five extensive droughted/nondefoliated mesocosms) (Appendix 1).

\section{Tree propagation and pre-treatment culture}

For Experiment 1, root cuttings were collected from various aspen genotypes in two populations, the Intermountain West (collected in Utah) and the Great Lakes (collected in Wisconsin). The cytotype of each genotype was determined via flow cytometry as described in Mock et al. (2012) and triploid cytotypes were confirmed using mitotic chromosome counts. We used micropropagation techniques (similar to Donaldson and Lindroth (2004)) to generate ramets of aspen genotypes for each experiment. We rooted micro-cuttings of individual ramets in flats of potting soil (Metro-Mix 350, Sun Gro Horticulture, Agawam, MA, US) and then transferred them to 66-mL cone-shaped cells (RLC4 Cone-tainer cells, Stuewe \& Sons Inc., Tangent OR, USA). Ramets were grown under these conditions for six weeks during the spring of 2015. In early June of 2015, we out-planted 30 ramets from each of 32 aspen genotypes at the West Madison Agricultural Research Station. We planted eight diploid and eight triploid genotypes from each population. We placed 64 ramets, two per genotype, at randomly chosen locations within each of 15 mesocosms. Mesocosms were $80 \mathrm{~cm}$ in diameter, had a raised soil bed $(15 \mathrm{~cm}$ elevation) surrounded by plastic garden edging, and were covered with a sheet of white plastic $(0.025 \mathrm{~cm}$ thickness $)$ in order to retain moisture. Plots were watered by hand and by seasonal precipitation.

For Experiments 2 and 3, we used the same Wisconsin root material collected for Experiment 1. In October 2017, root cuttings from all genotypes were planted in 4-l plastic flats filled with equal parts of torpedo sand and silt-loam field topsoil (Keleney Topsoil, Madison, Wisconsin, USA). Once root cuttings produced new shoots, we cut them into sections of ca. $10 \mathrm{~cm}$ length. Shoots were individually grown in $0.5-1$ pots $(60 \%$ 
torpedo sand, $40 \%$ field topsoil) and received $2 \mathrm{~g}$ of 6-month-release fertilizer (Nutricote total, Type 100 Blend, NPK 13-13-13, Arystra Lifescience, Broadway, NY, USA). By May 2018, shoots had developed into $\sim 40 \mathrm{~cm}$ tall trees. These were planted into outdoor mesocosms $(1.5 \times 1.5 \mathrm{~m})$ in a $20 \mathrm{~cm}$ deep layer of $60 \%$ torpedo sand and $40 \%$ field topsoil. One tree of each genotype was planted in each mesocosm (i.e., eight different diploids and eight different triploids per mesocosm). A randomly selected triploid tree was always planted next to a randomly selected diploid tree. To minimize potential edge effects, a border of single "buffer trees" ( $P$. tremuloides) was planted around the experimental trees of each mesocosm. All trees were planted at a $20 \times 20 \mathrm{~cm}$ spacing. One week after planting, each tree received $3.5 \mathrm{~g}$ of 6 -month-release fertilizer. Trees were watered frequently and allowed to grow for an additional eight weeks before applying the experimental treatments.

\section{Experimental treatments}

All trees were afforded access to similar resource levels, and remained undisturbed, for the entire duration of Experiment 1. In Experiment 2, eggs of white-marked tussock moths (Orgyia leucostigma) were obtained from the Canadian Forest Service (Sault Ste. Marie, Ontario, Canada). Eggs and hatched caterpillars were kept in climate chambers $\left(24{ }^{\circ} \mathrm{C}, 50-70 \%\right.$ humidity, 16:8 L:D light cycle) and were reared on wheat germ based Bell diet (Bell et al. 1981) to the fourth larval stadium. On July 17-18, 2018 we placed four fourthstadium caterpillars onto each of the experimental trees in each of ten mesocosms. Trees in the remaining 12 mesocosms received no larvae. Caterpillars were confined to trees in nylon mesh bags and allowed to feed on the entire tree for two days. Larvae were then removed and the defoliation was manually completed to a consistent $50 \%$ level across all leaves on all trees, using pinking shears. This method allowed us to incorporate the cues derived from natural herbivory with a standardized amount of foliar tissue removal (Stevens et al. 2007). Control trees (no defoliation) were covered with empty mesh bags for two days.

Several strategies were implemented to control the soil water content of the mesocosms in Experiment 2. To intercept rainfall, we installed transparent, plastic covers over all 22 mesocosms. To prevent infiltration of water from surrounding soil, the soil layer in each mesocosm was elevated on top of a 7.5-cm high layer of perforated plastic flats. A layer of root barrier fabric was also placed between the soil layer and the supporting plastic flats. Finally, the soil surface in each mesocosm was covered with a 6 -cm layer of leaf mulch to reduce evaporative drying. The drought stress treatment was applied to five mesocosms of defoliated trees and six mesocosms of undefoliated trees. Water was withheld for 7-12 days until most trees began to wilt, whereupon the mesocosm was watered to soil saturation. This procedure was repeated for 37 days, until the end of the study. Control mesocosms were watered to saturation every 2-4 days.

In Experiment 3, trees were defoliated (beginning on July 25, 2018, in five of the ten additional mesocosms) and soil water content was controlled using the same approaches outlined above for Experiment 2, except that, beginning July 27, 2018, all mesocosms were subjected to an extended drought stress treatment. Namely, water was withheld until all leaves from at least 12 of the 16 trees in a mesocosm had turned completely brown and the shoot tip meristems had died, upon which the mesocosm was watered to soil saturation. Consequently, mesocosms containing nondefoliated trees were re-watered 12-17 days after drought stress initiation, whereas mesocosms containing defoliated trees were re-watered 17-21 days after drought stress initiation. Starting with the initial re-watering date, mesocosms were watered frequently for an additional 42 days, at which time all trees were harvested (see below). Because of flooding by an extreme rain event in the middle of the experiment, two mesocosms of the defoliation treatment were eliminated.

\section{Measurements of tree traits}

\section{Tree growth}

To account for the typically substantial variation in initial tree size, stem height ( $h$, from soil surface to apical $\mathrm{bud} /$ meristem) and basal diameter $(d)$ of every tree were measured at the beginning of each experiment. These data were used to calculate initial $d^{2} h$, which is a metric highly and linearly correlated with tree 
biomass in young aspen (Stevens et al. 2007). Observed genotype-level relationships between initial $d^{2} h$ and tree weight afforded estimates of the latter for all non-harvested trees at the outset of growth measurement in Experiment 1. This size proxy also served as an effective covariate in analyses of variation in aboveground tree weight, which was quantified at the end of Experiments 2 and 3 using a destructive harvest. At harvest, all tissues were separated, roots (only harvested in Experiment 1) were rinsed free of soil, and fresh leaf area (without petioles) was measured using an LI-3100 (Li-Cor Biosciences, Lincoln, NE, USA).

In Experiment 1, initial $h$ and $d(2 \mathrm{~cm}$ above soil surface) were measured on July 23, and 10 trees per genotype (across six mesocosms) were harvested (including roots) on September 15. Specific leaf area (SLA, total fresh leaf area/ total leaf dry weight), leaf weight ratio (LWR, total leaf dry weight/ total tree dry weight [including roots]) and relative growth (RG, the $l n$ of final tree dry weight [including roots] - the $l n$ of initial tree dry weight [estimated from initial $\left.\left.d^{2} h\right]\right)$. In Experiment $2, d(4.5 \mathrm{~cm}$ above soil surface) and $h$ were measured just prior to defoliation and the onset of drought treatment (July 17). Stem height was also measured on each tree just prior to aboveground destructive harvest on August 27. SLA, total leaf dry weight and final tree dry weight (without roots) were measured. In Experiment $3, d(4.5 \mathrm{~cm}$ above soil surface) and $h$ were measured just before the onset of defoliation and drought treatments. On September 18, $d$ and $h$ were again measured for all trees. All trees were harvested 42 days after initial re-watering. In this case, intact stem sections, newly grown tissue (new side shoots, petioles and leaves that developed after the stress treatment application), and old leaves that developed before the stress treatments were separated and dried. Before drying, the surface area of a randomly selected subset of 15-21 newly grown leaves (without petioles) per tree was measured again using the LI-3100 and the SLA was calculated. All leaves were then dried and total leaf weight and tree weight (without roots) were calculated.

\section{Phytochemistry}

To compare cytotype and genotypic variation in phytochemistry and its response to environmental stress, leaves were harvested in roughly the middle of Experiments 1 and 2. In Experiment 1, we collected all foliage from the crowns of 12 trees per genotype (across five mesocosms) on July 23, 2015. In Experiment 2, leaves were collected evenly across the different treatments on August 17-24, 2018. From each tree, three fully expanded, young leaves were collected from the upper third of the tree crown. All leaves collected from defoliated trees showed signs of damage. In both experiments, leaves were collected under moist soil conditions and were vacuum-dried to constant mass and then stored at $-20^{\circ} \mathrm{C}$ to preserve labile phytochemical constituents. Concentrations of condensed tannins were analyzed using the acid butanol method of Porter et al. (1985) standardized against purified condensed tannins from P. tremuloides. Levels of the salicinoid phenolic glycosides tremulacin, tremuloidin, salicin and salicortin were quantified using ultra-high-performance liquid chromatography-mass spectrometry as described by Rubert-Nason et al. (2017). Leaf nitrogen concentration was measured using near-infrared reflectance spectroscopy (Rubert-Nason et al. 2013) verified against a subset of the samples analyzed using combustion gas chromatography (Thermo Flash EA1112 elemental analyzer [Thermo Finnigan, Milan, Italy]).

\section{Leaf physiology}

In Experiment 1, we measured light-saturated rates of net photosynthesis $\left(A_{\text {area }}, \mu \mathrm{mol} \mathrm{m} \mathrm{m}^{-2} \mathrm{~s}^{-1}\right)$ and stomatal conductance $\left(g_{\mathrm{s}}, \mathrm{mol} \mathrm{m}^{-2} \mathrm{~s}^{-1}\right)$ on fully expanded, sunlit leaves from four ramets per genotype, using an LI6400XT portable photosynthesis system with a broadleaf cuvette (Li-Cor Biosciences, Lincoln, NE, USA), during several mornings under clear to partly cloudy skies in late July, 2015. Cuvette temperature was set at $25^{\circ} \mathrm{C}$, photosynthetic photon flux density (PPFD) was $2000 \mathrm{mmol} \mathrm{m} \mathrm{m}^{-2}$, and the reference $\mathrm{pCO}_{2}$ was $40 \mathrm{~Pa}$. Relative humidity in the sample cuvette was between $60-70 \%$.

In Experiment 2, pre-dawn leaf water potential $\left(\Psi_{\mathrm{PD}}\right)$, light-saturated $A_{\text {area }}, g_{\mathrm{s}}$, and the maximum and operating efficiencies of photosystem II were measured, using the LI-6400XT portable photosynthesis system 
with a pulse amplitude modulation (PAM) fluorometer attached to the broadleaf cuvette, between July 21 and August 26, 2018. All traits were measured during 12 sessions. Each session consisted of two steps that were executed on the same day. First, $\Psi_{\mathrm{PD}}$ was measured from each of three trees growing in one mesocosm of each treatment combination. The selected trees were evenly distributed within a mesocosm and $\Psi_{\mathrm{PD}}$ from at least one diploid and one triploid tree was measured per mesocosm. $\Psi_{\mathrm{PD}}$ was measured between 0400-0530 h using a pressure chamber (PMS Instrument Company, Albany OR, USA). In one additional session, we quantified $\Psi_{\mathrm{PD}}$ and leaf physiological traits from only two mesocosms, of which one was exposed to drought stress and defoliation and the other was exposed to drought stress only. During the experiment, every mesocosm was selected two or three times for measurements. Mesocosms subjected to drought stress were measured at different stages of soil dry down. In a second step, leaf gas-exchange and variable chlorophyll fluorescence were measured on fully expanded, young leaves from all trees growing in the previously selected mesocosms (i.e., four mesocosms, 16 trees per mesocosm). During measurements, leaves in the cuvette were exposed to a photosynthetic photon flux of $1800 \mu \mathrm{mol} \mathrm{m} \mathrm{m}^{-2} \mathrm{~s}^{-1}$. The reference $\mathrm{CO}_{2}$ partial pressure was 40 $\mathrm{Pa}$, and the cuvette temperature was set at $25^{\circ} \mathrm{C}$. We did not control vapor pressure deficit between leaf and cuvette air, which ranged from 1.4-1.9 kPa. Measurements were taken on sunlit foliage between 0900-1300h. From August 18 through August 25, gas exchange was also measured at a cuvette $\mathrm{CO}_{2}$ partial pressure $\left(p \mathrm{CO}_{2}\right)$ ranging from 7.5 to $25 \mathrm{~Pa}$ on sunlit foliage from all trees of three mesocosms that were neither drought stressed nor defoliated. The observed relationship between photosynthesis $\left(A_{\text {area }}\right)$ and intercellular $p \mathrm{CO}_{2}\left(C_{\mathrm{i}}\right)$ was used to estimate $V_{\text {cmax }}\left(\mu \mathrm{mol} \mathrm{CO} \mathrm{CO}^{-2} \mathrm{~s}^{-1}\right)$, the maximum velocity of $\mathrm{RuBP}$ carboxylation, employing a trend-fitting method that minimized the total sums of squares for differences between observed versus predicted $A$ (Long and Bernacchi 2003). Estimates relied on Michaelis-Menten constants for $\mathrm{CO}_{2}$ $\left(K_{\mathrm{c}}\right)$ and oxygen $\left(K_{\mathrm{o}}\right)$, as well as photosynthetic compensation $p \mathrm{CO}_{2}\left(\Gamma^{*}\right)$, derived using formulae from Long and Bernacchi (2003). Because we did not account for the influence of mesophyll conductance on $\mathrm{CO}_{2}$ diffusion into the chloroplast (Dillaway and Kruger 2010), our derived $V_{\text {cmax }}$ values are "apparent" (Bernacchi et al. 2013) and based on $C_{\mathrm{i}}$ rather than chloroplastic $p \mathrm{CO}_{2}\left(C_{\mathrm{c}}\right)$.

\section{Statistical analyses}

For Experiment 1, Linear Mixed Models (LMMs) were used to evaluate the impacts of the explanatory variables ploidy, geographic origin (population), and their interaction on the various growth, allocational, morphological and leaf physiological traits. We accounted for genotypic variation by treating the variable genotype as random intercepts. In addition, block was included as a random intercept in each LMM. Individual RG values were normalized for initial tree weight (estimated from initial $d^{2} h$ values). The normalized values were then used as model response variables. Individual LWR values were normalized for tree dry weight. Prior to any normalization, the relationship between the response and the normalizing variable was explored and, if necessary, ln- or square root transformed to meet the model assumptions of normality and homoscedasticity.

For Experiment 2, LMMs were used to explore the roles of the explanatory variables ploidy, drought, defoliation and their interactions on the various growth, allocational, morphological phytochemical and leaf physiological traits. To account for the effect of genotypic variation, genotype and all possible genotype $\times$ stress interactions were modeled as random intercepts. In addition, we also included block as a random intercept in our models. Individual values of final above ground tree dry weights were normalized for variation in individual initial $d^{2} h$ values. The normalized values were then used as model response variables. To assess aboveground biomass allocation to foliage, total leaf weights were normalized for final tree dry weights. To quantify how much stem mass a tree allocated to height growth (i.e., how "lanky" a tree was), final height values were normalized for variation in final stem dry weight.Response and the normalizing variables were lnor square root transformed if necessary to meet the model assumptions of normality and homoscedasticity.

The impacts of ploidy, genotype, and defoliation on leaf physiology in Experiment 2 were explored with 
LMMs as described above. Drought-stress treatments resulted in various soil-dry down stages at different points in time which could not be reliably modeled with our LMMs models. Therefore, we focused on only well-watered trees in our analyses. Because physiological trait measurements were taken multiple times from each tree, average values across all measurements per tree were calculated and used for statistical analyses. For drought-stressed trees, we examined the relationship between $A_{\text {area }}$ and $\Psi_{\mathrm{PD}}$ for each genotype in both defoliation treatments using a three-parameter, Weibull-type vulnerability curve with the equation:

$\left.f i(y)=A_{m} a x e^{(}-(x / b)^{c}\right)$

where $x$ is the absolute value of the difference between $\Psi_{\mathrm{PD}}$ corresponding to a particular photosynthetic measurement and the least negative $\Psi_{\mathrm{PD}}$ observed during the study. The difference was used to avoid potential overestimation of $A_{\max }$ (or $g_{\max }$ ). Multi-parameter Weibull-type vulnerability curves are typically used to describe how tree trait respond to changes in drought stress, as they account for the often-observed relative unresponsiveness of trees when experiencing mild stress (Bateman et al. 2018; Vico and Porporato 2008; Wolfe et al. 2016). We calculated for each genotype the curve parameter values $A_{\max }, b$ and $c$ based on minimization of the sum of squared differences between the observed and predicted values for $A_{\text {area }}$ at different stages of drought stress. We then generated LMMs with curve parameter values as response variables and ploidy, defoliation and their interaction as explanatory variables and genotype as random intercepts. If necessary, response variables were transformed to meet model assumptions as described above.

In Experiment 3, the effects of ploidy, genotype, and defoliation on tree growth, morphological and allocational traits were evaluated using LMMs as described above. Individual values of final above ground tree dry weights and dry weight of newly produced tissue were normalized for initial $d^{2} h$. Total leaf weight was normalized for total final tree dry weight.

Analyses were conducted with R 4.0.4 (R Core Team 2021). Linear mixed effects models (LMMs) were fitted using the "lme4" package (version 1.1-20, Bates et al. (2014)). LMMs were subjected to type III ANOVAs with Satterthwaite's method to produce a summary of the F and p statistics. We calculated the relative explanatory power of individual fixed effects by quantifying the semi-partial $\mathrm{R}^{2}$ to assess the relative importance of each fixed effect while accounting for all other fixed and random effect terms. The r2beta function in the package "r2glmm" was used for calculating semi-partial $\mathrm{R}^{2}$ statistics (v. 0.1 .2 ,(Jaeger et al. 2017)). We then calculated the proportion of total variance explained by all fixed effects $\left(\mathrm{R}^{2}\right.$ marginal $)$ and all random effects $\left(\mathrm{R}^{2}\right.$ conditional $-\mathrm{R}^{2}$ marginal $)$. Lastly individual random effects were calculated by dividing the variance for that effect by the total variance. The getvariance function of the "insight" package (v. 0.13.1(Lüdecke et al. 2019)) was used to calculate proportions of model variances explained by the total fixed effects, the total random effects, and the model residuals as well as for quantifying individual variance contributions of each random intercept of an LMM. The significance of random effects was tested with loglikelihood-ratio tests using the ranova function of the "ImerTest" package (v.3.1-3 ) (Kuznetsova et al. 2017). Weibull curve parameters were generated in Excel solver.

\section{RESULTS}

\section{Experiment 1: Ploidy effects on traits of nonstressed trees across populations}

After 93 days of growth, genotypes from the Great Lakes, Wisconsin (WI) population, had on average, more than a 3-fold higher growth rate than those from the Intermountain West, Utah (UT) (Fig. 1, Appendix 2). Differences between populations explained over $45 \%$ of the total observed variation in relative growth (effect size plot, Fig.1). RG did not differ significantly between ploidy levels (Fig. 1, Appendix 2). Population differences in LWR indicated that, across ploidy levels, WI genotypes invested on average $72 \%$ more in leaves than did UT genotypes (Fig.1, Appendix 1). Specific leaf area (SLA) averaged 19\% higher across WI genotypes than in UT genotypes (not shown, Appendix 1). LWR and SLA differences between cytotypes were slight and nonsignificant.

All leaf phytochemical traits differed significantly between populations. Levels of total salicinoid phenolic glycosides were on average, 17\% higher in WI compared with UT genotypes (Fig.1, Appendix 2). WI ge- 
notypes also exceeded UT genotypes with respect to foliar concentrations of individual phenolic glycosides tremulacin (36\%) and salicin (124\%). Salicortin levels, however, did not differ between WI and UT genotypes. Condensed tannin levels were 33\% higher (not shown, Appendix 2) and nitrogen levels were 15\% higher in WI than in UT genotypes (Fig. 1, Appendix 2). In no case did measures of phytochemistry differ significantly between cytotypes.

A population contrast was also observed for light-saturated photosynthesis $(29 \%$ higher in WI than in UT genotypes) and stomatal conductance (21\% higher in WI than in UT genotypes). Again, however, none of the leaf physiological parameters differed significantly between ploidy levels (Fig.1, Appendix 2).

Genotypic differences significantly influenced all growth, allocation, phytochemical and leaf physiological traits. Genotypic differences had a higher explanatory importance for phytochemical and leaf physiological trait variations than population differences (effect size plots, Fig.1). In contrast, growth traits variations were driven more by differences between populations than among genotypes.

\section{Experiment 2: Ploidy effects on tree traits and their response to stress}

Among Wisconsin genotypes, we found no difference between diploid and triploid trees for any aboveground growth traits when averaged across all stress treatments (Fig. 2, Appendix 3). In contrast, genotypic differences significantly influenced most growth traits. Tree genotype was particularly relevant for determining final height and SLA and explained $39 \%$ and $30 \%$ of the total observed variance in these two traits (effect size plots, Fig. 2).

Tree growth and biomass allocation traits were affected by drought stress, defoliation or their interaction (Fig. 2). At a given tree weight, drought-stressed trees had on average $8 \%$ lower leaf weights than did watered trees. Similarly, defoliation reduced total leaf weight and SLA. For total tree weight we observed significant drought $\times$ defoliation interactions. Nondefoliated, watered trees had $25 \%$ greater total weight when compared with nondefoliated, drought-stressed trees. However, when trees were defoliated, drought-treatment differences disappeared. Similar, albeit less pronounced interaction effects between drought and defoliation treatments were also observed for total leaf weight. Cytotypes showed similar responses to drought stress and defoliation (no significant ploidy $\times$ treatment interactions were found). Furthermore, we did not observe any genotype $\times$ treatment interactions.

Concentrations of most chemical compounds did not differ between the cytotypes when averaged across all treatments (Fig. 3, Appendix 3, 4). The only exception was tremulacin, which was $17 \%$ higher in triploid trees than in diploids (Appendix 4). However, differences in ploidy levels could mainly be attributed to a single triploid genotype (Appendix 4). Genotypic differences significantly affected most chemical compounds (Fig. 3, Appendix 3,4). Genotypic effects accounted for 30\% of the variation in total salicinoid phenolic glycosides and almost $50 \%$ of the variation in condensed tannins (Fig. 3, effect size plot).

Drought stress and defoliation did not affect concentrations of total phenolic glycoside levels. Drought, however, led to increased levels of the phenolic glycosides salicortin (7\% increase) and salicin (44\% increase) (Appendix 3). Condensed tannin concentrations increased by $25 \%$ under drought stress and by $56 \%$ in response to defoliation. Nitrogen levels increased by $11 \%$ under drought stress, and decreased minimally $(<5 \%)$ due to defoliation. Ploidy levels as well as the different genotypes responded similarly to drought stress and defoliation (no significant ploidy $\times$ treatment or genotype $\times$ treatment interactions).

Differences in ploidy affected photosynthetic rates (Fig. 4a) and $V_{\text {cmax }}$ (Appendix 5). Well-watered triploids exhibited $11 \%$ higher photosynthetic rates and $23 \%$ higher $V_{\text {cmax }}$. Cytotype explained almost $20 \%$ of the total variation in $V_{\text {cmax }}$ (Fig. 4a, Appendix 5, effect size plots). No other leaf physiological traits were affected by cytotype levels. Genotype significantly affected variation of photosynthetic rate, stomatal conductance and the quantum effeciency of PSII, explaining 10-20\% of the variation in all traits (Fig. 4a, Appendix 5).

In well-watered trees, defoliation affected only stomatal conductance, which was $3 \%$ higher in defoliated 
than in nondefoliated trees (Appendix 5). No significant ploidy $\times$ treatment or genotype $\times$ treatment interactions were found. For trees that were exposed to drought stress, we observed similar vulnerability curve progressions for diploid and triploid trees of the same defoliation treatment. No significant impact of ploidy or ploidy $\times$ defoliation interactions was detected for any curve parameter (Fig. 4b, Appendix 6). However, defoliation treatments per se significantly affected net photosynthesis and stomatal conductance responses to drought. Photosynthetic rates of nondefoliated trees plummeted when experiencing $\Psi_{\mathrm{PD}}$ of -7 bars or lower. In contrast, photosynthesis rates of defoliated trees decreased more gradually. Defoliated trees were still photosynthetically active, even when experiencing severe drought stress. Correspondingly, we found significant differences between curve parameters describing the defoliated and nondefoliated tree curves (Fig. 4b, Appendix 6).

\section{Experiment 3: Ploidy effects under drought recovery}

Diploid and triploid trees differed in growth responses during recovery from extensive drought stress. Across defoliation treatments, triploids produced $35 \%$ more new tissue than did diploid trees (Fig. 5). None of the other growth traits was affected by cytotype differences (Fig. 5, Appendix 7, 8). In contrast, genotype significantly affected all growth traits except new tissue production and explained 10-20\% of the variation in the affected traits (Fig.5, Appendix 7, 8).

Trees that were defoliated prior to drought showed higher growth responses during drought recovery than trees that were not defoliated. Defoliated trees allocated more of their stem mass to height growth (increased by $10 \%$ ), produced $45 \%$ more new tissue during recovery, and exceeded nondefoliated trees by $19 \%$ in total weight at the end of the experiment (Appendix 7). Defoliation also caused trees to invest more in leaf production (leaf weight at a given tree weight increased by 30\%) and in thicker, smaller leaves (SLA decreased by 9\%) (Fig. 5, Appendix 7). Cytotypes as well as genotypes responded similarly to the defoliation treatment (no ploidy $\times$ treatment or genotype $\times$ treatment interactions).

\section{DISCUSSION}

In this research, we disentangled two components of genetic diversity, genotypic variation and ploidy level, and quantified their relevance for growth, biomass allocation, morphology, phytochemistry, and physiological traits. Population and genotypic differences typically obscured ploidy effects for both a wide array of traits and responses of those traits to drought and defoliation. One key illustration of this is observed variation in tree growth, along with it physiological, morphological and allocational determinants, among nonstressed trees in Experiment 1. Ploidy level had no clearly discernible influence on growth, which differed substantially across populations as well as genotypes within each population. This variation was consistent with corresponding population/genotype differences in LWR, SLA, and, to a lesser extent, $A_{\text {area }}$, the three principal growth determinants in young trees (Kruger and Volin 2006). Only a few traits, such as drought resilience, photosynthetic performance and levels of certain chemical defenses, showed subtle, albeit significant, differences between diploid and triploid aspen. Our research highlights that, despite the recognized importance of ploidy for tree ecology, ploidy effects may pale in contrast to genotypic effects in determining functional trait expression and trait responses to in highly diverse tree species. Similar findings were recently reported by DeRose et al. (2022) for natural populations of mature aspen in northern Utah.

Tremblingaspen is known for its exceptionally high genetic and trait variation (Callahan et al. 2013; Jelinski and Cheliak 1992; Mitton and Grant 1996). Our finding that the vast majority of trait variation was driven by genotypic rather than ploidy differences confirms the well-documented importance of genotypic diversity for determining tree environmental adaptation and evolution (Petit and Hampe 2006; Westerband et al. 2021).

Regarding ploidy effects on phytochemistry, the observed difference in foliar tremulacin level between triploids and diploids (Appendix 4) accords with results from studies on other plant systems finding that polyploidy 
can lead to altered secondary chemistry (Gaynor et al. 2020; Park et al. 2021; Te Beest et al. 2012). The ploidy effect on tremulacin level, however, was moderate (absolute differences of $\sim 1.5 \% \mathrm{dw}$ across defoliation and drought treatments) and mainly driven by a single triploid genotype that showed increased defense levels. In contrast to our results, DeRose et al. (2022) reported for mature aspen in northern Utah that triploids exhibited $21 \%$ higher levels of salicinoid phenolic glycosides than diploids. Similar to our findings, though, expression of condensed tannins did not differ between cytotypes (DeRose et al. 2022).

The influence of ploidy level on light-saturated photosynthesis in our Wisconsin genotypes (Fig. 4a) is also generally consistent with previous findings. Greer et al. (2018) reported that mature triploid aspen clones in the Rocky Mountains exhibited higher net carbon assimilation rates than did diploid clones. In contrast to our results, however, the key driver of enhanced photosynthetic performance in mature triploids was increased stomatal conductance rather than heightened rubisco activity ( $V_{\text {cmax }}$, Appendix 5 ). Regardless, given the central role that leaf photosynthetic performance plays in plant carbon balance, differences in photosynthesis between diploid and triploid trees might ultimately drive other trait-level divergences between the two cytotypes. For example, increased photosynthetic rates in triploids possibly contributed, via greater availability of assimilated carbon, to higher tremulacin levels in triploid foliage. Enhanced photosynthetic activity would also likely increase biomass growth in triploids, but corresponding growth differences were not observed in our study. We acknowledge, however, that our ability to thoroughly assess links between growth and its determinants is precluded by the absence of data on belowground biomass allocation. Other studies on mature aspen have found that triploid genotypes exceed diploids in stem growth rates and stem diameter (DeRose et al. 2015).

The absence of marked cytotype differences in trait response to defoliation and/or recurring drought in our study (no ploidy $\times$ treatment interactions) agrees with results from research on other plant species such as strawberry, Fragaria vesca (Wei et al. 2020) the herbaceous perennial Rhodohypoxis baurii (Mtileni et al. 2021), and the annual herb Mercurialis annua (Vilas and Pannell 2017). Yet a growing body of research documents that polyploidy in plants confers a benefit under environmental stress (Van de Peer et al. 2021). For example, allotetraploid grass (Brachypodium distachyon) (Manzaneda et al. 2012), autotetraploid Rangpur lime hybids (Citru limonia $\times$ Citrus sinensis) (Allario et al. 2013) and polyploid gum Arabic tree (Acacia senegal) (Diallo et al. 2016) were more drought tolerant than their diploid counterparts. Several reasons may explain the discrepancy between our results and the aforementioned examples. Firstly, the extent to which polyploidy can confer increased stress tolerance can differ greatly among plant species and ecological context (Fox et al. 2020; Van de Peer et al. 2021). Moreover, the importance of cytotype for stress adaptation may depend on the source of cytotype variation (e.g. polyploids that arise within a species [autopolyploidy] or from hybridization of two distinct species [allopolyploidy]), the number of multiplied chromosome sets (triploidy, tetraploidy, etc.) or gene dosage effects (Bastiaanse et al. 2019; Van de Peer et al. 2021; Van de Peer et al. 2017). Finally, ploidy effects have rarely been explored in the context of intraspecific genotypic variation. Our findings underscore the importance of considering conventional genotypic variation when exploring the ecological relevance of ploidy effects in future studies.

Cytotype differences affected trait response to environmental stress only in one case: triploid genotypes displayed a slightlygreater drought resilience than did diploid genotypes, as measured via increased production of new lateral shoot tissue during post-drought recovery (Fig. 5). As a consequence, when growing in regions frequented by drought, young triploid trees might outcompete young diploid trees. A cytotype difference in drought resilience could help explain the comparative abundance of triploid clones in the arid regions of North America (Mock et al. 2012; but see Latutrie et al. (2019)). However, recent studies by Blonder et al. (2021), Blonder et al. (2022) and (Greer et al. 2018) found that triploid mature aspen appear to be more susceptible to drought stress than diploids. These findings suggest that cytotype effects on drought-tolerance in aspen may vary among developmental stages.

Defoliation rivaled or exceeded polyploidy with respect to the magnitude of its positive impact on drought resilience (Fig. 5, Appendix 7). This outcome can be explained in part by the fact that leaves of defoliated trees sustained stomatal opening and photosynthesis at soil moisture deficits well beyond the threshold 
causing pronounced stomatal closure (and decreased photosynthesis) in foliage of nondefoliated trees (Fig. 4b, Appendix 6). A similar influence of defoliation on leaf photosynthetic response to water stress has been observed in other studies (McGraw et al. 1990; Pinkard et al. 2011). It may stem from the effects of defoliation on the fundamental balance between transpirational demand and moisture supply, which is thought to exert considerable control over stomatal behavior (Sperry et al. 1998). Consistent with the observed growth responses of droughted trees in this study (Fig. 2) and others (Jacquet et al. 2014; Pinkard et al. 2011), a comparative increase in leaf carbon gain would help mitigate the negative effects of defoliation on biomass growth. Correspondingly, the increase would allow defoliated trees to accumulate more carbohydrate reserves and, during subsequent drought recovery, invest more resources into biomass production relative to nondefoliated trees. These phenomena and their underlying mechanisms warrant further investigation, as we have not found published corroboration of this impact of defoliation impact on drought recovery.

In conclusion, our study shows that in young trembling aspen, genotypic differences were key determinants of functional trait variation, and the magnitude of that variation obscured potential ploidy effects. Upon accounting for genotypic effects, only a few traits differed between diploid and triploid trees. Triploid trees exhibited slightly higher levels of defense and photosynthesis, as well as higher resilience to extended drought events. Hence, while genotypic differences are key determinants of aspen's adaptation to environmental stress, young triploid trees might possess additional subtle advantages when confronted with drought or herbivory. With the advance of climate change, forests are increasingly exposed to both environmental stressors (Aber et al. 2001; Seidl et al. 2017). Accordingly, the possibility that herbivore-mediated defoliation, in addition to genetic determinants, can buffer negative drought effects is an important consideration when assessing the consequences of future stressors on forest ecosystems.

\section{FUNDING}

This work was supported by the Swiss National Science Foundation [P2BEP3_175254] and USDA National Institute of Food and Agriculture grants 2016-67013-25088 and WIS01651. Participation of coauthor KM was supported by the Utah Agricultural Experiment Station, and this is UAES publication \#9516.

\section{ACKNOWLEDGEMENTS}

We thank Chris Cole, Jack Schaefer, Allyson Richins, Andrew Helm and the Walnut street greenhouse staff for help with setting up the experiments, Mark Zierden for assistance with the chemical analyses, Rick Jellen for cytotype identification and Rebecca Best for advice regarding statistical analyses.

\section{LITERATURE CITED}

Aartsma Y, Leroy B, van der Werf W, Dicke M, Poelman EH, Bianchi FJ (2019) Intraspecific variation in herbivore-induced plant volatiles influences the spatial range of plant-parasitoid interactions. Oikos 128:7786 doi:https://doi.org/10.1111/oik.05151

Aber J, Neilson RP, McNulty S, Lenihan JM, Bachelet D, Drapek RJ (2001) Forest processes and global environmental change: predicting the effects of individual and multiple stressors: We review the effects of several rapidly changing environmental drivers on ecosystem function, discuss interactions among them, and summarize predicted changes in productivity, carbon storage, and water balance. BioScience 51:735-751 doi:https://doi.org/10.1641/0006-3568(2001)051[0735:FPAGEC]2.0.CO;2

Albert CH, Thuiller W, Yoccoz NG, Soudant A, Boucher F, Saccone P, Lavorel S (2010) Intraspecific functional variability: extent, structure and sources of variation. Journal of Ecology 98:604-613 doi:https://doi.org/10.1111/j.1365-2745.2010.01651.x 
Allario T et al. (2013) Tetraploid Rangpur lime rootstock increases drought tolerance via enhanced constitutive root abscisic acid production. Plant, Cell \& Environment 36:856-868 doi:https://doi.org/10.1111/pce.12021

Allen CD, Breshears DD, McDowell NG (2015) On underestimation of global vulnerability to tree mortality and forest die-off from hotter drought in the Anthropocene. Ecosphere 6:1-55 doi:https://doi.org/10.1890/ES15-00203.1

Anderegg WR et al. (2015) Tree mortality from drought, insects, and their interactions in a changing climate. New Phytologist 208:674-683 doi:https://doi.org/10.1111/nph.13477

Anderegg WR, Kane JM, Anderegg LD (2013a) Consequences of widespread tree mortality triggered by drought and temperature stress. Nature Climate Change 3:30-36 doi:https://doi.org/10.1038/nclimate1635

Anderegg WR, Plavcova L, Anderegg LD, Hacke UG, Berry JA, Field CB (2013b) Drought's legacy: multiyear hydraulic deterioration underlies widespread aspen forest die-off and portends increased future risk. Global Change Biology 19:1188-1196 doi:https://doi.org/10.1111/gcb.12100

Ashraf MI, Bourque CP-A, MacLean DA, Erdle T, Meng F-R (2015) Estimation of potential impacts of climate change on growth and yield of temperate tree species. Mitigation and Adaptation Strategies for Global Change 20:159-178 doi:https://doi.org/10.1007/s11027-013-9484-9

Barker HL, Holeski LM, Lindroth RL (2019) Independent and interactive effects of plant genotype and environment on plant traits and insect herbivore performance: a meta-analysis with Salicaceae. Functional Ecology 33:422-435 doi:https://doi.org/10.1111/1365-2435.13249

Barton KE, Valkama E, Vehvilainen H, Ruohomaki K, Knight TM, Koricheva J (2015) Additive and nonadditive effects of birch genotypic diversity on arthropod herbivory in a long-term field experiment. Oikos 124:697-706 doi:https://doi.org/10.1111/oik.01663

Bastiaanse $\mathrm{H}$ et al. (2019) A comprehensive genomic scan reveals gene dosage balance impacts on quantitative traits in Populus trees. Proceedings of the National Academy of Sciences 116:13690-13699 doi:https://doi.org/10.1073/pnas.1903229116

Bateman A, Lewandrowski W, Stevens JC, Munoz-Rojas M (2018) Ecophysiological indicators to assess drought responses of arid zone native seedlings in reconstructed soils. Land Degradation \& Development 29:984-993 doi:https://doi.org/10.1002/ldr.2660

Bates D, Machler M, Bolker B, Walker S (2014) Fitting linear mixed-effects models using lme4. Journal of Statistical Software 67:1-48

Batllori E et al. (2020) Forest and woodland replacement patterns following drought-related mortality. Proceedings of the National Academy of Sciences:202002314 doi:https://doi.org/10.1073/pnas.2002314117

Bell R, Owens C, Shapiro M, Tardif J (1981) Mass rearing and virus production. In: The gypsy moth: Research toward integrated pest management, vol 1584. US Department of Agriculture Washington, DC, USA, pp 599-655. doi:https://ageconsearch.umn.edu/record/158053

Bernacchi CJ, Bagley JE, Serbin SP, RUIZ-VERA UM, Rosenthal DM, Vanloocke A (2013) Modelling C3 photosynthesis from the chloroplast to the ecosystem. Plant, Cell \& Environment 36:1641-1657 doi:https://doi.org/10.1111/pce.12118

Bishop M, Furniss TJ, Mock KE, Lutz JA (2019) Genetic and spatial structuring of Populus tremuloides in a mixed-species forest of southwestern Utah, USA. Western North American Naturalist 79:63-71 doi:https://doi.org/10.3398/064.079.0107

Blonder B et al. (2022) Remote sensing of cytotype and its consequences for canopy damage in quaking aspen. Global change biology In press: doi:https://doi.org/10.1111/gcb.16064 
Blonder B et al. (2021) Cytotype and genotype predict mortality and recruitment in Colorado quaking aspen (Populus tremuloides). Ecological Applications:e02438 doi:https://doi.org/10.1002/bes2.1930

Bradshaw AD (1965) Evolutionary significance of phenotypic plasticity in plants. Advances in Genetics 13:115-155 doi:https://doi.org/10.1016/S0065-2660(08)60048-6

Callahan CM, Rowe CA, Ryel RJ, Shaw JD, Madritch MD, Mock KE (2013) Continental-scale assessment of genetic diversity and population structure in quaking aspen (Populus tremuloides). Journal of Biogeography 40:1780-1791 doi:https://doi.org/10.1111/jbi.12115

Chen L, Huang JG, Dawson A, Zhai L, Stadt KJ, Comeau PG, Whitehouse C (2018) Contributions of insects and droughts to growth decline of trembling aspen mixed boreal forest of western Canada. Global Change Biology 24:655-667 doi:https://doi.org/10.1111/gcb.13855

Cooper HF, Grady KC, Cowan JA, Best RJ, Allan GJ, Whitham TG (2019) Genotypic variation in phenological plasticity: reciprocal common gardens reveal adaptive responses to warmer springs but not to fall frost. Global Change Biology 25:187-200 doi:https://doi.org/10.1111/gcb.14494

DeRose RJ, Gardner R, L, Lindroth RL, Mock K, E. (2022) Polyploidy and growth-defense tradeoffs in natrual populations of western quaking aspen. Journal of Chemical Ecology In press

DeRose RJ, Mock KE, Long JN (2015) Cytotype differences in radial increment provide novel insight into aspen reproductive ecology and stand dynamics. Canadian Journal of Forest Research 45:1-8 doi:https://doi.org/10.1139/cjfr-2014-0382

Diallo AM, Nielsen LR, Kjaer ED, Petersen KK, Raebild A (2016) Polyploidy can confer superiority to West African Acacia senegal (L.) Willd. trees. Frontiers in Plant Science 7:821 doi:https://doi.org/10.3389/fpls.2016.00821

Dillaway DN, Kruger EL (2010) Thermal acclimation of photosynthesis: a comparison of boreal and temperate tree species along a latitudinal transect. Plant, Cell \& Environment 33:888-899 doi:https://doi.org/10.1111/j.1365-3040.2010.02114.x

Donaldson JR, Lindroth RL (2004) Cottonwood leaf beetle (Coleoptera: Chrysomelidae) performance in relation to variable phytochemistry in juvenile aspen (Populus tremuloides Michx.). Environmental Entomology 33:1505-1511 doi:https://doi.org/10.1603/0046-225x-33.5.1505

Elias T, Little E (1980) Checklist of United States trees (native and naturalized). US Department of Agriculture, Washington D. C. doi:https://doi.org/10.2307/2806152

Estravis-Barcala M, Mattera MG, Soliani C, Bellora N, Opgenoorth L, Heer K, Arana MV (2020) Molecular bases of responses to abiotic stress in trees. Journal of Experimental Botany 71:3765-3779 doi:https://doi.org/10.1093/jxb/erz532

Every AD, Wiens D (1971) Triploidy in Utah aspen. Madrono 21:138-147

Fox DT, Soltis DE, Soltis PS, Ashman T-L, Van de Peer Y (2020) Polyploidy: a biological force from cells to ecosystems. Trends in Cell Biology doi:https://doi.org/10.1016/j.tcb.2020.06.006

Gaynor ML, Lim-Hing S, Mason CM (2020) Impact of genome duplication on secondary metabolite composition in non-cultivated species: a systematic meta-analysis. Annals of Botany 126:363-376 doi:https://doi.org/10.1093/aob/mcaa107

Gazol A, Camarero J, Anderegg W, Vicente-Serrano S (2017) Impacts of droughts on the growth resilience of Northern Hemisphere forests. Global Ecology and Biogeography 26:166-176 doi:https://doi.org/10.1111/geb.12526

Greer BT, Still C, Cullinan GL, Brooks JR, Meinzer FC (2018) Polyploidy influences plantenvironment interactions in quaking aspen (Populus tremuloides Michx.). Tree Physiology 38:630-640 
doi:https://doi.org/10.1093/treephys/tpx120

Huang G, Rymer PD, Duan H, Smith RA, Tissue DT (2015) Elevated temperature is more effective than elevated [CO2] in exposing genotypic variation in Telopea speciosissima growth plasticity: implications for woody plant populations under climate change. Global Change Biology 21:3800-3813 doi:https://doi.org/10.1111/gcb.12990

Jacquet J-S, Bosc A, O'Grady A, Jactel H (2014) Combined effects of defoliation and water stress on pine growth and non-structural carbohydrates. Tree Physiology 34:367-376 doi:https://doi.org/10.1093/treephys/tpu018

Jaeger BC, Edwards LJ, Das K, Sen PK (2017) An R 2 statistic for fixed effects in the generalized linear mixed model. Journal of Applied Statistics 44:1086-1105

Jelinski DE, Cheliak W (1992) Genetic diversity and spatial subdivision of Populus tremuloides (Salicaceae) in a heterogeneous landscape. American Journal of Botany 79:728-736 doi:https://doi.org/10.1002/j.15372197.1992.tb13647.x

Kolb TE et al. (2016) Observed and anticipated impacts of drought on forest insects and diseases in the United States. Forest Ecology and Management 380:321-334 doi:https://doi.org/10.1016/j.foreco.2016.04.051

Kreyling J, Puechmaille SJ, Malyshev AV, Valladares F (2019) Phenotypic plasticity closely linked to climate at origin and resulting in increased mortality under warming and frost stress in a common grass. Ecology and Evolution 9:1344-1352 doi:https://doi.org/10.1002/ece3.4848

Kruger EL, Volin JC (2006) Reexamining the empirical relation between plant growth and leaf photosynthesis. Functional Plant Biology 33:421-429 doi:https://doi.org/10.1071/FP05310

Kuznetsova A, Brockhoff PB, Christensen RH (2017) lmerTest package: Tests in linear mixed effects models. Journal of Statistical Software 82:1-26 doi:https://doi.org/10.18637/jss.v082.i13

Latutrie M, Toth EG, Bergeron Y, Tremblay F (2019) Novel insights into the genetic diversity and clonal structure of natural trembling aspen (Populus tremuloides Michx.) populations: A transcontinental study. Journal of Biogeography 46:1124-1137 doi:https://doi.org/10.1111/jbi.13574

Lecina-Diaz J et al. (2021) Characterizing forest vulnerability and risk to climate-change hazards. Frontiers in Ecology and the Environment 19:126-133 doi:https://doi.org/10.1002/fee.2278

Levin DA (1983) Polyploidy and novelty in flowering plants. The American Naturalist 122:1-25 doi:https://doi.org/10.1086/284115

Li WL, Berlyn GP, Ashton PMS (1996) Polyploids and their structural and physiological characteristics relative to water deficit in Betula papyrifera (Betulaceae). American Journal of Botany 83:15-20 doi:https://doi.org/10.2307/2445949

Long SP, Bernacchi C (2003) Gas exchange measurements, what can they tell us about the underlying limitations to photosynthesis? Procedures and sources of error. Journal of Experimental Botany 54:23932401 doi:https://doi.org/10.1093/jxb/erg262

Ludecke D, Waggoner PD, Makowski D (2019) Insight: A unified interface to access information from model objects in R. Journal of Open Source Software 4:1412 doi:https://doi.org/10.21105/joss.01412

Madlung A (2013) Polyploidy and its effect on evolutionary success: old questions revisited with new tools. Heredity 110:99-104 doi:https://doi.org/10.1038/hdy.2012.79

Manzaneda AJ, Rey PJ, Bastida JM, Weiss-Lehman C, Raskin E, Mitchell-Olds T (2012) Environmental aridity is associated with cytotype segregation and polyploidy occurrence in Brachypodium distachyon (Poaceae). New phytologist 193:797-805 doi:https://doi.org/10.1111/j.1469-8137.2011.03988.x 
McGraw JB, Gottschalk KW, Vavrek MC, Chester A (1990) Interactive effects of resource availabilities and defoliation on photosynthesis, growth, and mortality of red oak seedlings. Tree Physiology 7:247-254 doi:https://doi.org/10.1093/treephys/7.1-2-3-4.247

Meng F, Peng M, Pang H, Huang F (2014) Comparison of photosynthesis and leaf ultrastructure on two black locust (Robinia pseudoacacia L.). Biochemical Systematics and Ecology 55:170-175 doi:https://doi.org/10.1016/j.bse.2014.03.025

Millar CI, Stephenson NL (2015) Temperate forest health in an era of emerging megadisturbance. Science 349:823-826 doi:https://doi.org/10.1126/science.aaa9933

Mitton JB, Grant MC (1996) Genetic variation and the natural history of quaking aspen. Bioscience 46:25-31 doi:https://doi.org/10.2307/1312652

Mock KE et al. (2012) Widespread triploidy in western North American aspen (Populus tremuloides). PLoS One 7 doi:https://doi.org/10.1371/journal.pone.0048406

Mock KE, Rowe C, Hooten MB, Dewoody J, Hipkins V (2008) Clonal dynamics in western North American aspen (Populus tremuloides). Molecular Ecology 17:4827-4844 doi:https://doi.org/10.1111/j.1365294x.2008.03963.x

Mtileni M, Venter N, Glennon K (2021) Ploidy differences affect leaf functional traits, but not water stress responses in a mountain endemic plant population. South African Journal of Botany 138:76-83 doi:https://doi.org/10.1016/j.sajb.2020.11.029

Niinemets U (2010) Responses of forest trees to single and multiple environmental stresses from seedlings to mature plants: past stress history, stress interactions, tolerance and acclimation. Forest Ecology and Management 260:1623-1639 doi:https://doi.org/10.1016/j.foreco.2010.07.054

Niwa Y, Sasaki Y (2003) Plant self-defense mechanisms against oxidative injury and protection of the forest by planting trees of triploids and tetraploids. Ecotoxicology and Environmental Safety 55:70-81 doi:https://doi.org/10.1016/s0147-6513(02)00095-7

Park CH, Park YE, Yeo HJ, Yoon JS, Park S-Y, Kim JK, Park SU (2021) Comparative Analysis of Secondary Metabolites and Metabolic Profiling between Diploid and Tetraploid Morus alba L. Journal of Agricultural and Food Chemistry 69:1300-1307 doi:https://doi.org/10.1021/acs.jafc.0c06863

Petit RJ, Hampe A (2006) Some evolutionary consequences of being a tree. Annual Review of Ecology, Evolution and Systematics 37:187-214 doi:https://doi.org/10.1146/annurev.ecolsys.37.091305.110215

Pinkard E, Eyles A, O'Grady A (2011) Are gas exchange responses to resource limitation and defoliation linked to source: sink relationships? Plant, Cell \& Environment 34:1652-1665 doi:https://doi.org/10.1111/j.1365-3040.2011.02361.x

Porter LJ, Hrstich LN, Chan BG (1985) The conversion of procyanidins and prodelphinidins to cyanidin and delphinidin. Phytochemistry 25:223-230 doi:https://doi.org/10.1016/S0031-9422(00)94533-3

R Core Team (2021) R: a language and environment for statistical computing. R Foundation for Statistical Computing. See http://www.r-project.org/. Vienna, Austria

Rehfeldt GE, Ferguson DE, Crookston NL (2009) Aspen, climate, and sudden decline in western USA. Forest Ecology and Management 258:2353-2364 doi:https://doi.org/10.1016/j.foreco.2009.06.005

Rubert-Nason KF, Couture JJ, Major IT, Constabel CP, Lindroth RL (2015) Influence of genotype, environment, and gypsy moth herbivory on local and systemic chemical defenses in trembling aspen (Populus tremuloides). Journal of Chemical Ecology 41:651-661 doi:https://doi.org/10.1007/s10886-015-0600-z

Rubert-Nason KF, Holeski LM, Couture JJ, Gusse A, Undersander DJ, Lindroth RL (2013) Rapid phytochemical analysis of birch (Betula) and poplar (Populus) foliage by near-infrared reflectance spectroscopy. 
Analytical and Bioanalytical Chemistry 405:1333-1344 doi:https://doi.org/10.1007/s00216-012-6513-6

Rubert-Nason KF, Couture JJ, Gryzmala EA, Townsend PA, Lindroth RL (2017) Vernal freeze damage and genetic variation alter tree growth, chemistry, and insect interactions. Plant, Cell \& Environment 40:2743-2753 doi:https://doi.org/10.1111/pce.13042

Samaniego L et al. (2018) Anthropogenic warming exacerbates European soil moisture droughts. Nature Climate Change 8:421-426 doi:https://doi.org/10.1038/s41558-018-0138-5

Schueler S et al. (2013) Adaptive genetic diversity of trees for forest conservation in a future climate: a case study on Norway spruce in Austria. Biodiversity and Conservation 22:1151-1166 doi:https://doi.org/10.1007/s10531-012-0313-3

Seidl R et al. (2017) Forest disturbances under climate change. Nature Climate Change 7:395-402 doi:https://doi.org/10.1038/nclimate3303

Silfver T, Roininen H, Oksanen E, Rousi M (2009) Genetic and environmental determinants of silver birch growth and herbivore resistance. Forest Ecology and Management 257:2145-2149 doi:https://doi.org/10.1016/j.foreco.2009.02.020

Sperry JS, Adler F, Campbell G, Comstock J (1998) Limitation of plant water use by rhizosphere and xylem conductance: results from a model. Plant, Cell \& Environment 21:347-359 doi:https://doi.org/10.1046/j.1365-3040.1998.00287.x

Stanke H, Finley AO, Domke GM, Weed AS, MacFarlane DW (2021) Over half of western United States' most abundant tree species in decline. Nature Communications 12:451 doi:https://doi.org/10.1038/s41467020-20678-z

Stevens MT, Waller DM, Lindroth RL (2007) Resistance and tolerance in Populus tremuloides: genetic variation, costs, and environmental dependency. Evolutionary Ecology 21:829-847 doi:https://doi.org/10.1007/s10682-006-9154-4

Te Beest M, Le Roux JJ, Richardson DM, Brysting AK, Suda J, Kubešová M, Pyšek P (2012) The more the better? The role of polyploidy in facilitating plant invasions. Annals of Botany 109:19-45 doi:https://doi.org/10.1093/aob/mcr277

Valladares F, Gianoli E, Gómez JM (2007) Ecological limits to plant phenotypic plasticity. New Phytologist 176:749-763 doi:https://doi.org/10.1111/j.1469-8137.2007.02275.x

Van de Peer Y, Ashman T-L, Soltis PS, Soltis DE (2021) Polyploidy: an evolutionary and ecological force in stressful times. The Plant Cell 33:11-26 doi:https://doi.org/10.1093/plcell/koaa015

Van de Peer Y, Mizrachi E, Marchal K (2017) The evolutionary significance of polyploidy. Nature Reviews Genetics 18:411 doi:https://doi.org/10.1038/nrg.2017.26

Vico G, Porporato A (2008) Modelling C3 and C4 photosynthesis under water-stressed conditions. Plant and Soil 313:187-203 doi:https://doi.org/10.1007/s11104-008-9691-4

Vilas JS, Pannell JR (2017) No difference in plasticity between different ploidy levels in the Mediterranean herb Mercurialis annua. Scientific Reports 7:1-10 doi:https://doi.org/10.1038/s41598-017-07877-3

Wei N, Du Z, Liston A, Ashman TL (2020) Genome duplication effects on functional traits and fitness are genetic context and species dependent: studies of synthetic polyploid Fragaria. American journal of botany 107:262-272 doi:10.1002/ajb2.1377

Westerband A, Funk J, Barton K (2021) Intraspecific trait variation in plants: a renewed focus on its role in ecological processes. Annals of Botany 127:397-410 doi:https://doi.org/10.1093/aob/mcab011 
Wolfe BT, Sperry JS, Kursar TA (2016) Does leaf shedding protect stems from cavitation during seasonal droughts? A test of the hydraulic fuse hypothesis. New Phytologist 212:1007-1018 doi:https://doi.org/10.1111/nph.14087

Worrall JJ, Rehfeldt GE, Hamann A, Hogg EH, Marchetti SB, Michaelian M, Gray LK (2013) Recent declines of Populus tremuloides in North America linked to climate. Forest Ecology and Management 299:35-51 doi:https://doi.org/10.1016/j.foreco.2012.12.033

Wurst S, Van Dam NM, Monroy F, Biere A, Van der Putten WH (2008) Intraspecific variation in plant defense alters effects of root herbivores on leaf chemistry and aboveground herbivore damage. Journal of Chemical Ecology 34:1360-1367 doi:https://doi.org/10.1007/s10886-008-9537-9

Zolkos SG, Jantz P, Cormier T, Iverson LR, McKenney DW, Goetz SJ (2015) Projected tree species redistribution under climate change: implications for ecosystem vulnerability across protected areas in the Eastern United States. Ecosystems 18:202-220 doi:https://doi.org/10.1007/s10021-014-9822-0

\section{FIGURES}
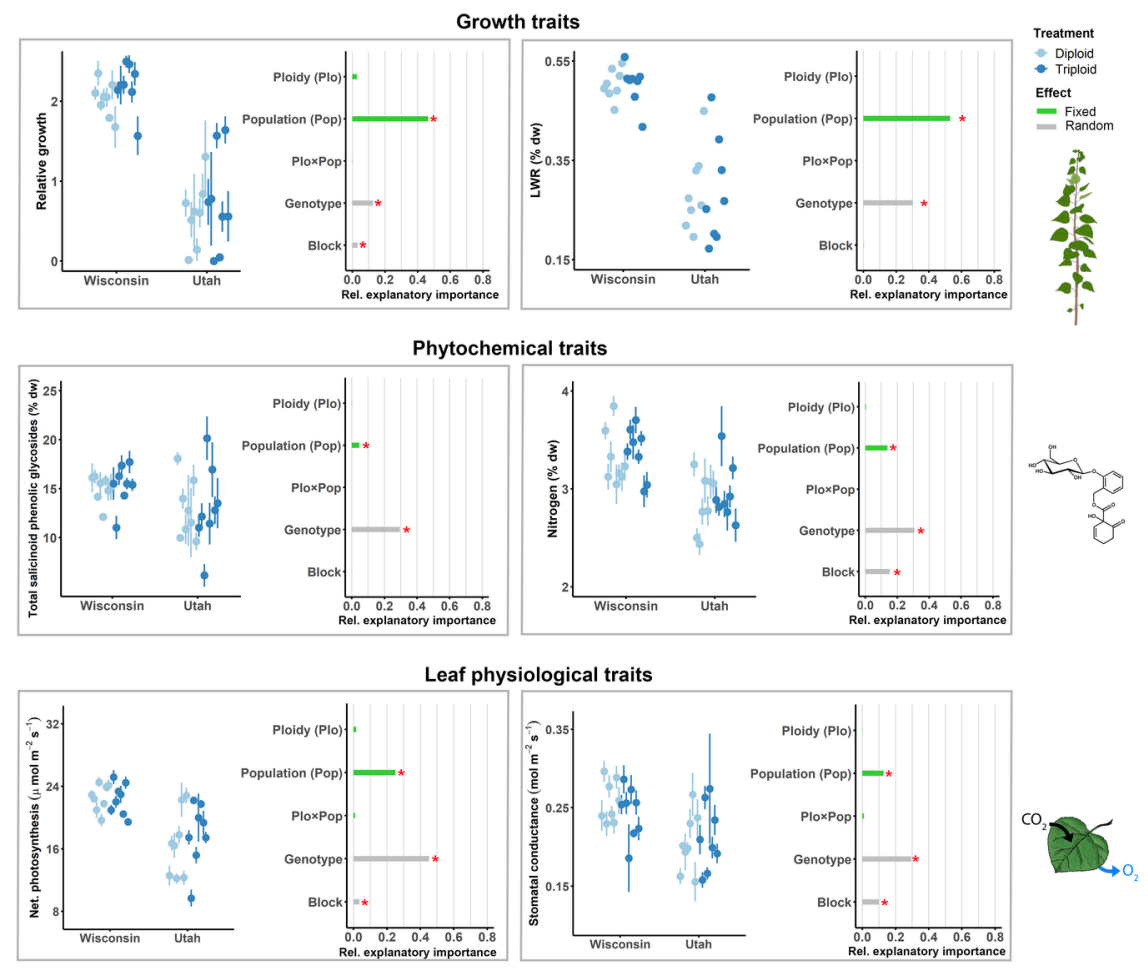

Figure 1: This is a caption

- Fig. 1 Genotype means ( \pm SE) (left panels) and effect sizes (right panels) illustrating ploidy level and source population effects on growth, phytochemical and leaf physiological traits (different boxes). Genotype means show each of eight different diploid and triploid genotypes from the Great Lakes population (Wisconsin) and Intermountain West population (Utah). Data points are horizontally jittered to reduce overlapping. Statistics for fixed effects and random intercepts are shown in Appendix 2. LWR $=$ leaf weight ratios (including roots), $\mathrm{dw}=$ dry weight. 


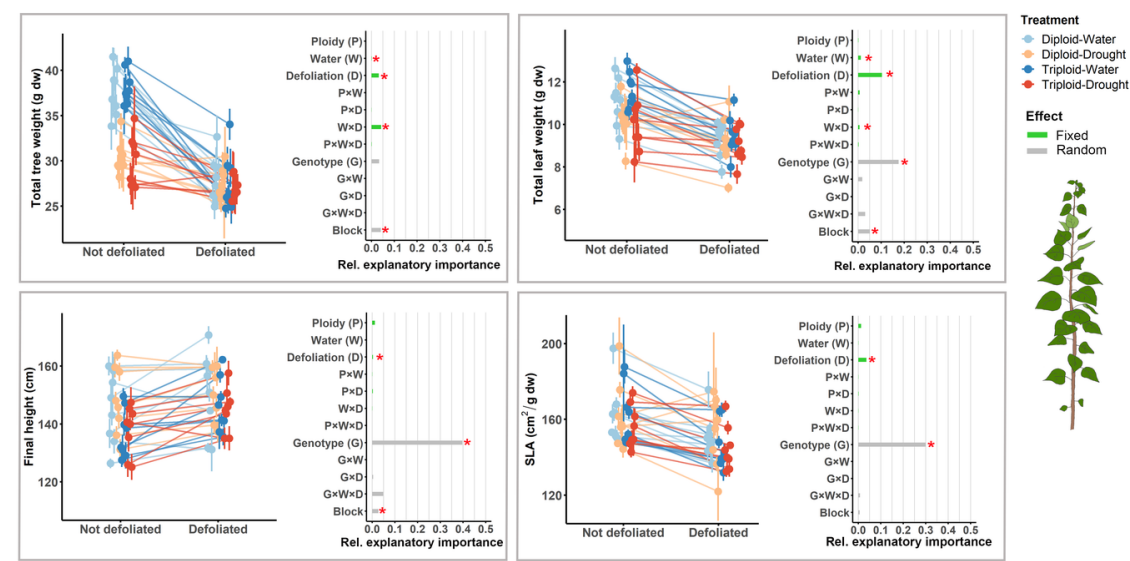

Figure 2: Fig 2 Norm of reaction plots (left panels) and effect size plots (right panels) illustrating the effects of ploidy level, drought stress and defoliation on growth, morphological and allocational traits (different boxes). Norm of reaction plots show mean $( \pm \mathrm{SE}$ ) responses of eight different diploid and triploid genotypes when exposed to all possible combinations of drought stress and defoliation. Data points are horizontally jittered to reduce overlapping. The corresponding effect size plots show the relative explanatory importance of each fixed effect as the partial $\mathrm{R}^{2}$ value and the proportion of variance explained by each random effect in the trait model. Asterisks indicate statistical significance $(\mathrm{p}<0.050)$. Statistics for fixed effects and random intercepts are shown in Appendix 3. SLA $=$ specific leaf area, $\mathrm{dw}=$ dry weight.
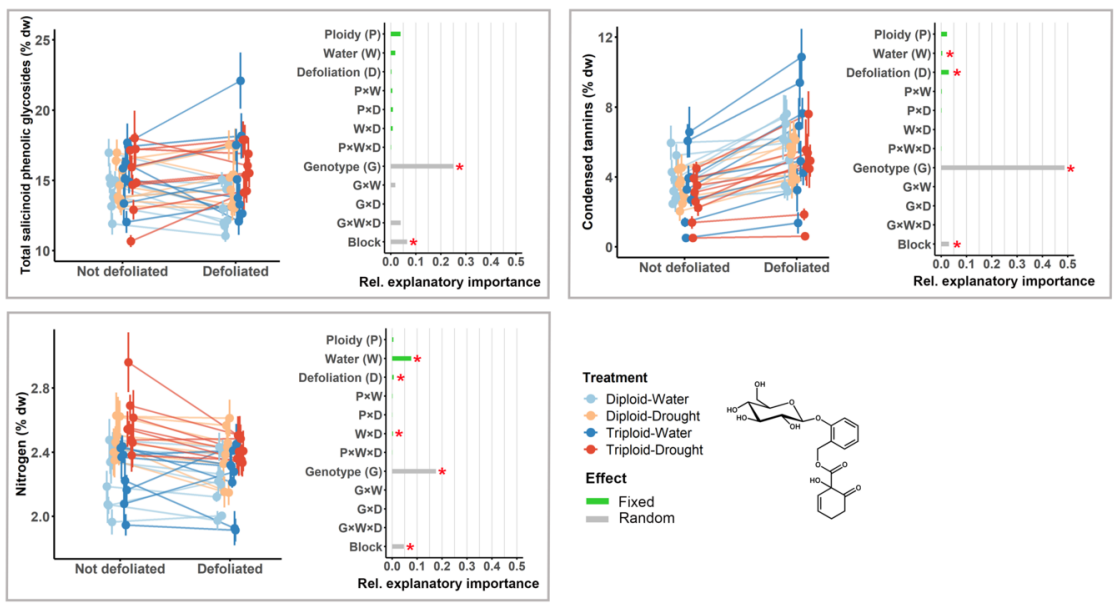

Figure 3: This is a caption

Fig. 3. Norm of reaction plots (left panels) and effect size plots (right panels) illustrating the effects of ploidy level, drought stress and defoliation on phytochemical traits (different boxes). Norm of reaction plots show mean $( \pm \mathrm{SE})$ responses of eight different diploid and triploid genotypes when exposed to all possible combinations of drought stress and defoliation. Data points are horizontally jittered to reduce overlapping. The corresponding effect size plots show the relative explanatory importance of each fixed effect as the partial $\mathrm{R}^{2}$ value and the proportion of variance explained by each random effect in the trait model. Asterisks indicate 
statistical significance $(\mathrm{p}<0.050)$. Statistics for fixed effects and random intercepts are shown in Appendix $3 . \mathrm{dw}=$ dry weight.
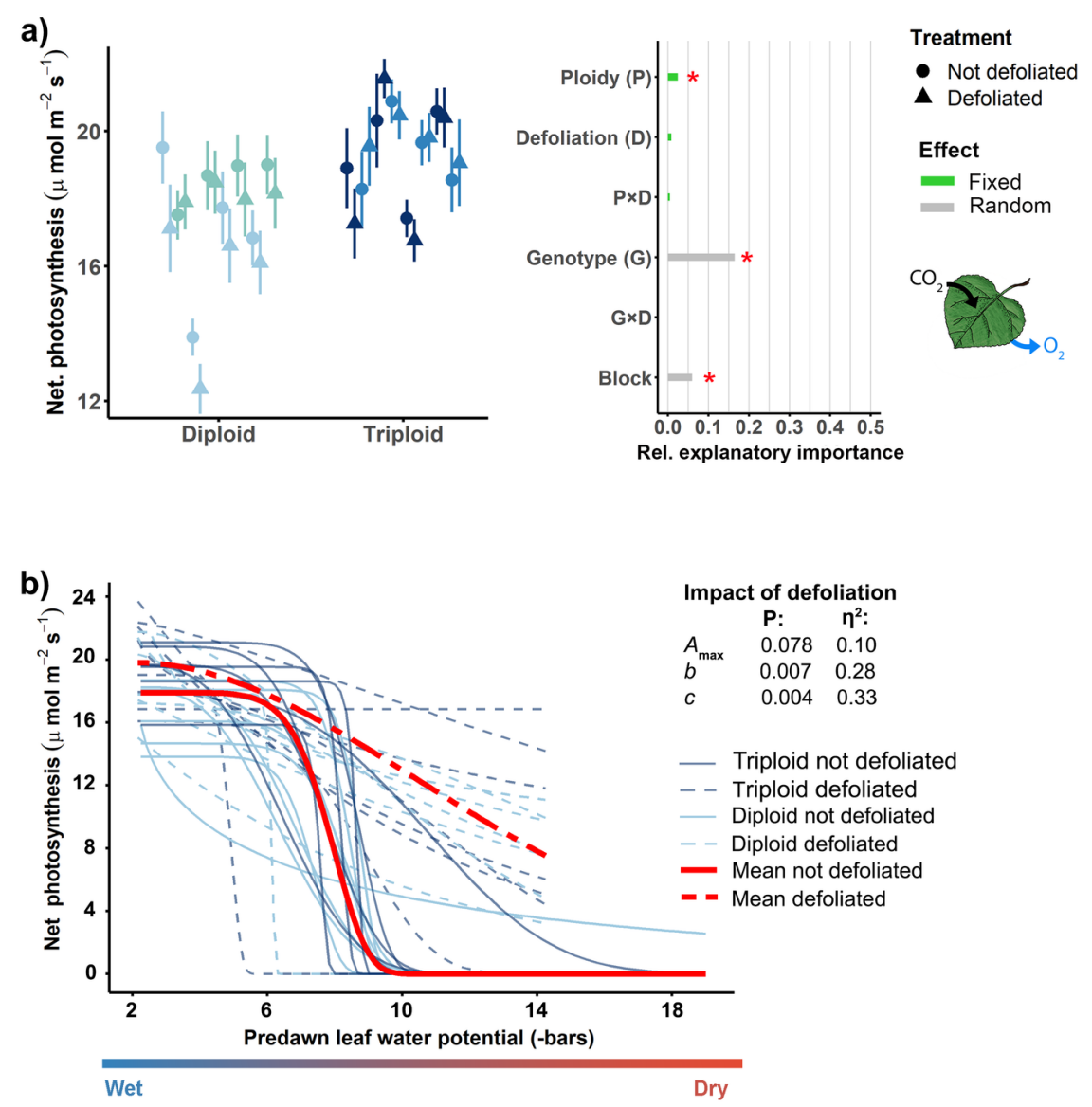

Figure 4: This is a caption

Fig. 4. a) Genotype mean values ( $\pm \mathrm{SE}$ ) (left panel) and effect size plot (right panel) illustrating the effects of ploidy level and defoliation on net photosynthesis $\left(A_{\max }\right)$ in well-watered trees. Mean values are shown for eight different diploid and triploid genotypes when defoliated or undefoliated. Data points are horizontally jittered to reduce overlapping. The corresponding effect size plots show the relative explanatory importance of each fixed effect as the partial $\mathrm{R}^{2}$ value and the proportion of variance explained by each random effect in the trait model. Asterisks indicate statistical significance $(\mathrm{p}<0.050)$. Statistics for fixed effects and random intercepts are shown in Appendix 3. b) Photosynthesis vulnerability curves of defoliated and undefoliated diploid and triploid genotypes. Red trends were generated based on back-transformed means of ln-transformed genotype values for each of the curve-fitting parameters $\left(A_{\max }, b\right.$ and $\left.c\right)$. Transformation of genotype parameters lessened the undue influence of outlier values. Thin curves represent untransformed, individual genotypes. The impact of ploidy, defoliation and their interaction on the curve parameters $A_{\max }$, $b$ and $c$ was tested in models accounting for genotypic differences. Only values of model variables with $\mathrm{P}$ [?] 0.100 are shown. 

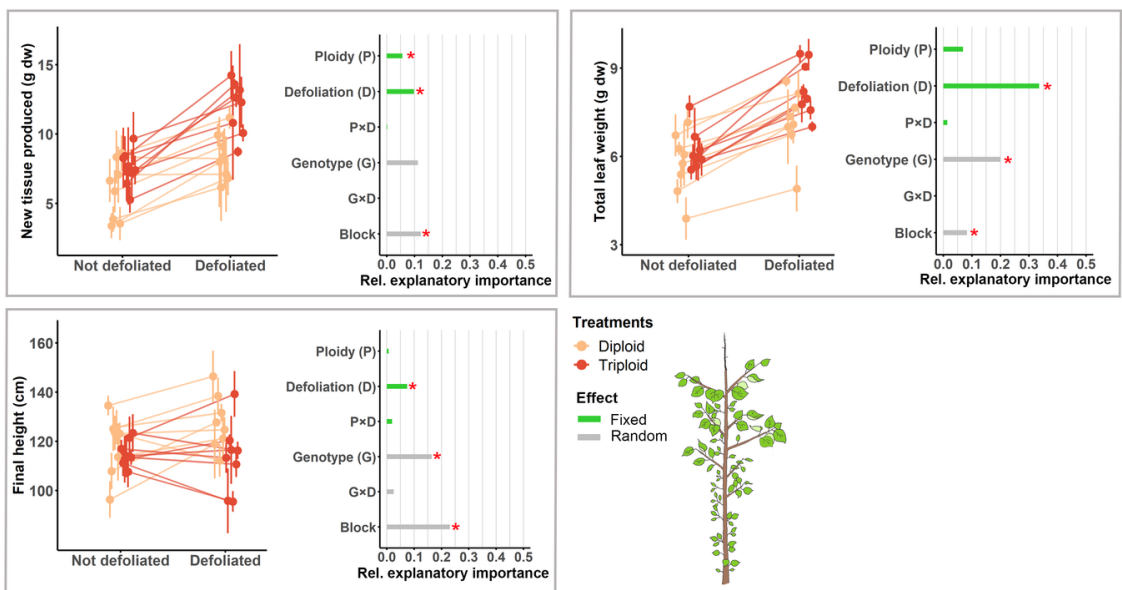

Figure 5: This is a caption

Norm of reaction plots (left panels) and effect size plots (right panels) illustrating the effects of ploidy level and defoliation on growth traits (different boxes) of trees recovering from a prolonged drought treatment. For each trait, norm of reaction plots show mean $( \pm \mathrm{SE})$ responses of eight different diploid and triploid genotypes when recovering from drought and having experienced either defoliation or no defoliation prior to drought. Data points are horizontally jittered to reduce overlapping. The corresponding effect size plots show the relative explanatory importance of each fixed effect as the partial $\mathrm{R}^{2}$ value and the proportion of variance explained by each random effect in the trait model. Asterisks indicate statistical significance $(\mathrm{p}<$ 0.050). Statistics for fixed effects and random intercepts are shown in Appendix 8. dw $=$ dry weight. 